\title{
Universality and Variation of Conceptual Metaphor of Love in Chinese and English
}

\author{
Zitu Lv \\ Changchun University of Science and Technology, China \\ Yining Zhang (corresponding author) \\ Changchun University of Science and Technology, China \\ Email: zhangyining0829@163.com
}

\begin{abstract}
Metaphors are so pervasive in expressing some abstract emotions such as love and anger that it seems that they play an important role in our expressing emotions. Love is a universal emotion shared by people from different countries. The paper discusses university and variation of conceptual metaphors of love in English and Chinese from cognitive angle.
\end{abstract}

Index Terms - conceptual metaphors, universality and variation

Metaphor is a way people construe the objective world, and it is the reflection of culture. The existence of one metaphorical concept in different nations and different cultures shows the university of metaphorical cognition and similarity of cognition among different nations. On the other hand, metaphorical concepts are somewhat culturally different because of the influence of different cultures. How foundational metaphor is to cultural understanding has been a matter of considerable debate, manifested in the question of whether cultural models are, at bottom, based on conceptual metaphors (Gibbs 1994; Lakoff 1993; Lakoff and Johnson 1999; Quinn 1991). But one thing is true, that is, the understanding of conceptual metaphor depends on the understanding of socio-cultural backgrounds. For example, in a culture with a tradition of Shamanism, it is not obvious that "lack of sensible behavior" would be automatically related with "madness" or "anger." Thus, we can say that culturally determined metaphors lead to different conceptualization of "sensible behavior" in different cultures.

\section{INTRODUCTION}

Our emotions are neither primitive nor 'natural', but rather intelligent, structured by concepts and judgments that we learn in a particular culture, through which we give our experience some shape and meaning"(Solimon,1990). According to Lakoff's experiential cognition, the physical experience of cognitive subjects plays a very important role in cognitive development, and forming of abstract concepts comes from the physical experience of cognitive subjects in certain environments. Culture influenced language greatly and the use of metaphor is carried out in the cultural environment and historical background. Because of the regional and cultural differences of English and Chinese, people living in different cultures act and behave differently, and have different physical experience. Thus, there is the conceptual metaphor WEST WIND IS WARMTH in English and EAST WIND IS WARMTH in Chinese. That is the reason why the famous British poet Shelly wrote in Ode to West Wind "thou breath of Autumn's being", "drive my dead thoughts", "to quicken a new birth", "The trumpet of a prophecy! If Winter comes, can spring be far behind?" While in chinese, west wind means coldness as in Autumn Thought from Ma Zhiyuan “古道西风瘦马。夕阳西下，断肠人在天 涯”. Meanwhile, Chairman Mao Zedong states “西风烈, 长空雁叫霜晨月”. In Chinese, west wind means coldness, bleakness, blight; while east wind means warmth and spring as in Xin Qiji's Lantern Festival “东风夜放花千树，更吹 落，星如雨” The understanding of conceptual metaphors is greatly constrained by the different cultures.

LOVE uses different source domains for different reasons, namely to convey information related to different concrete objects respectively. There are different systematic mapping between a source domain and a target domain because of different cultures.

\section{UNIVERSALITY OF LOVE METAPHORS}

The way in which human beings think and the way that they act are largely metaphorical. Not surprisingly, human beings communicate through language by means of conceptual systems that are essentially metaphorical. Since metaphor is considered as a set of systematic mappings between a source domain and a target domain, it is easy to find many shared conceptual metaphors in both English and Chinese. However, the shared conceptual metaphors in English and Chinese display variations in the metaphorical linguistic expressions.

When we are encountered with metaphors in English and Chinese, we can have a distinct impression that is a lot of non-universal metaphors exist in different languages. As shown in Chapter 3, universality and variation are both 
common. Love is one of many emotions we experience in a complex way which is finally not irrational but decidedly rational. In both English and Chinese, love is conceptualized as a journey, plant, fire, unity and so forth; while love is commonly viewed as commodity in English and as paired animals in Chinese.

As for the universality and variation of metaphors, we can resort to primary metaphors, which can be put together to form conceptual metaphors, such as LOVE IS JOURNEY, or LOVE IS FIRE, in which they function as conceptual correspondences or mappings between the source domain and the target domain.

Culture greatly influence what complex conceptual metaphors emerge from the primary metaphors. It is commonly believed that emotions are culturally dependent experiences, and language and the underlying conceptualization of emotional experience are culture-specific. English and Chinese belong to different cultures, which didn't have much contact with each other when conceptual metaphors evolved.

\section{VARIATION OF LOVE METAPHORS}

It is clear that a culture employs a particular source domain for the conceptualization of different target domains. Meanwhile, the set of conceptual metaphors are a particular target domain is roughly the same in English and Chinese, but English or Chinese shows a clear preference for some of the conceptual metaphors that are employed.

Universal primary experiences produce universal primary metaphors. Conceptual metaphor, in a great sense, depends on the universality of thinking models of easterners and westerners. However, it sometimes reflects its national cultural features, that is, nationality. Love is a common emotion of human beings, but the expression of love is somewhat culturally different. Chinese prefer to use some specific objects of natural forces, animals and plants to be the source domain; while Englishmen would like to take plants or natural forces as a whole to be the source domain. For example, LOVE IS PLANT is a typical conceptual metaphor in English, with "love grows in her/Their love flowered" to be the commonly found examples, but in Chinese some specific plants, such as twin lotus flowers on one stalk, are metaphorically used to represent love.

Metaphorical language allows speakers to make a variety of points about the corresponding experience. As mentioned above, Chinese resort to internal organs to express love, which are linked to five elements, that is, wood, fire, earth, metal and water, which are considered as the makeup of the universe according to ancient philosophy. Five-element theory takes different elements as different representatives of different feelings, and different feelings are related to different bodily organs. Since heart is the most important internal organs (heart, liver, spleen, lungs and kidneys), heart is always used to express love among human beings

Some conceptual metaphors are unique to either English or Chinese. As is mentioned in Chapter 3, Chinese and English share a lot of basic metaphorical source domains for love: journey, fire, plant, natural forces, and so forth. However, the fact is there are more conceptual metaphors concerning love in English than those in Chinese. Meanwhile, a lot of modern Chinese love metaphors are borrowed from or influenced by western cultures.

Chinese and English share a lot of basic metaphorical source domains for love: journey, fire, plant, natural forces, and so forth. There are some Chinese conceptual metaphors, which are not found in English, such as love-as-silk metaphor. The application of such metaphors reflects the more introverted character of speakers of Chinese, while the love-as-fire metaphor reflects the extroverted characteristic of English speakers. It is obvious that westerners talked about love with great passion and bravery, Chinese talked about love indirectly and tactfully. In the following part, some reasons for the variation of English and Chinese conceptual metaphors will be discussed from cross-cultural perspectives.

\section{REASONS FOR VARIATION}

Quinn claims that metaphors expressed in language are underlain by cultural models. Zoltán (2005) claims the causes of variation in metaphor can be grouped into 2 large classes: differential experience and differential cognitive preferences or styles. On the one hand, many of our metaphors vary because our experience as human beings also varies. And, on the other hand, our metaphors vary because the cognitive preferences and styles we put to use for the creation of abstract thought also vary. Physical environment, national personalities, thinking models, religious beliefs and cultural-ideological traits are mentioned respectively.

\section{A. Physical Environment}

People living in different physical environments construe the physical environments differently, and the metaphors they use vary, too. Universal embodiment associated with a target domain may be composed of different components, or distinct aspects. The different conceptual metaphors might be based on one aspect or component in one area and another in another area, let alone in different countries which are totally different in physical environments.

It is easy to discover that people living in Britain conceptualize metaphors differently from those in china. For example, spatial conceptualization changes because of the degree of contact between humans and animals. In Britain, people and dogs keep a close contact with each other, it is likely to find conceptual metaphors like DOGS ARE FRIENDS, such as in "Love me love my dog.", "You are a lucky dog."

Because of different physical environments, people focus on different native products. Agriculture is very important 
in Chinese history, which results in plenty of farm products to be the source domain when love is the target domain. In Chinese, love is mulberry and love is silk with mulberry and silk are the basic national farm products in China; While English involves farm products in English speaking countries, such as bread-and-cheese marriage. The English expression love in cottage has the counterpart in Chinese, which is couples of chaff-and-husks days. Similarly, both English and Chinese have the same metaphor LOVE IS PLANT. However, in Chinese the specific domain is jumby bean (love bean), in English the commonly employed domain is rose or even wild plant. The conceptual metaphor in English and Chinese is similar, but the entities to express the emotion are different because of the physical environmental differences.

\section{B. Different Personalities of English Speakers and Chinese Speakers}

When we are studying metaphorical expression of a conceptual metaphor, we should consider such factors as the literal meaning of the expression, the figurative meaning and the conceptual metaphor. It seems that in English it is internal considerations of external conditions that cause people in love to do something in certain ways, while external conditions make Chinese lovers do something in other ways. The reason why Chinese are more externally forced to act or make decisions than westerners is Chinese are more fatalistic when facing life, let alone emotions. Chinese people are likely to give in to forces that are believed to be beyond one's control.

A degree of extroversion is not easily found in Chinese culture, whereas westerners, especially Americans are eager to express their love openly and directly with examples like "I am burning with love", "my love is a red rose"

English speakers are passionate, romantic and daring in characteristics. In their eyes, love is the most pleasant thing in life. Without love, life is not interesting any more. Hence, they prefer to employ direct and passionate ways to express their emotions, and love is conceptualized as red, red rose, which symbolizes the passionate love between lovers.

Meanwhile, Chinese compare love as moon, and westerns as the sun because of the cultural difference. In Chinese culture, moon is praised and oft-quoted by ancient poets since moon is as gentle and indirect as love shared by ancient Chinese, while English people considered love as brilliant, powerful and mighty. Hence, in Chinese there are such sentences as 思君如满月, 夜夜减清辉, which show the pure and loyal love of the woman. However, in English there are expressions like "Juliet is the sun" in the following:

Romeo:

But soft, what light through yonder window breaks?

It is the east, and Juliet is the sun.

Arise, fair sun, and kill the envious moon,

Who is already sick and pale with grief

That thou, her maid, art far more fair than she.

Romeo And Juliet Act 2, scene 2, 2-6

Juliet is fairer and more brilliant than the moon is meant to be taken as Romeo's sincere belief. When Juliet appears above, on her balcony, she appears like the sun at dawn, her light overpowering the moon's merely reflected brilliance. This is just one in a long series of metaphorical associations of Juliet with light. Romeo feels that his love infinitely regresses and cannot be explained or rationally resolved or reduced to anything tangible but that he can only find the sun which vindicates and confirms his love of Juliet. Romeo is suggesting an elemental absolutism or natural truism to his love for Juliet.

\section{Different Thinking Models}

Metaphor is a way of showing people's thinking, and is influenced by people's thinking in the process of construing the world. Although human thinking models are of their own rules, which results in university of metaphors, thinking models of different nations cause the nationality of metaphors.

Metaphor is a way to embody thinking, and is influenced by individual way of thinking in the process of people's cognition of the world. Although the ways of thinking of peoples from different countries follow the same principle, and have something in common, ways of thinking of different nations vary, with specific features. Westerners are good at analysis and logic, thus ways of thinking are linear; whereas easterners are good at integration, and imaginative and dependent on intuition, which is circling in form. When the two ways of thinking are reflected on metaphoric conceptualization, Chinese uses more concrete objects in mapping, while English employs association and analogy to describe the corresponding target domain.

Influenced by modern industry, westerns emphasize individualism and materialism, which makes westerns take marriage as a contract and love as commodity, reflected in expressions as "I paid a lot for so little love". Westerns consider more about love when they consider to be married, and children or properties that are not closely related to love could not bind them.

\section{Different Religious Beliefs}

We equate insanity with the loss of sensible behavior that we judge them similar. This is less obvious than it may seem because such a judgment of similarity is dependent on cultural mediation. It is likely that unless a metaphor is based on some primary concept, or embodied experience as the work of Lakoff and Johnson in Philosophy in the Flesh 
supports in certain circumstances, the source domain is equally a product of some culturally dependent conceptualization.

Beside the different ways of thinking of English speakers and Chinese, different traditional cultures result in the different outlook of the world, which determines the choice of mapping and conceptualization of metaphors, with Chinese influenced deeply by Daoism, Confucianism, while westerners by Christianity.

The Chinese conceptual metaphor LOVE IS FATE is the typical example to illustrate the different cultural models of different nations. Chinese culture is influenced by Buddhism, Daoism and feudalism, which makes Chinese express love indirectly and implicitly. Chinese prefer Buddhist conceptualizations of states-of-being, rebirth and event structure for their reducibility to primary metaphors, which are constituted by culture-specific understandings. The Chinese word “缘分” (fate) comes from Buddhism. According to Buddhism, phenomena in the world are caused, including being a couple or being in love. Fate makes people get married or fall into love with each other, such as 十年修的同船渡, 百年 修的共枕眠.However, most westerners believe in Christianity and they are deeply influenced by Christianity, which results in the love conceptual metaphors related to Christianity or God. For example:

She worships the ground she walks on.

He is forever singing her praises.

Chinese culture is influenced by Buddhism, Daoism and feudalism, which makes Chinese express love indirectly and implicitly. If we survey the ancient Chinese poems, it is difficult for us to find the word love directly; However, the conceptualization of love in English language is so strongly influenced by the idea of Christianity, materialism, and individualism that westerners express their love directly and passionately. Stearns(1994) claims "in intense, spiritualized passion, couples hoped to find some of the same balm to the soul that religion had once....More concluded that true love was itself a religious experience." Let's take the following English and Chinese poems as examples:

Till a' the seas gang dry, my dear,

And the rocks melt wi' the sun;

And I will luve thee still, my dear,

While the sands o'life shall run.

Robert Burns A Red, Red Rose

上邪！吾欲与君相知, 长命无绝衰。山无陵, 江水为竭, 冬雷震震, 夏雨雪, 天地合, 乃敢与君绝! 一汉乐府古辞《上邪》

Both of the two poems express the everlasting love between lovers, with the English one stating that I will love you still, my dear, while the Chinese version expressing love by saying that nothing will separate us even when the rocks melt and the seas go dry.

\section{E. Cultural-ideological Traits}

"Basic conceptual metaphors are part of the common conceptual apparatus shared by members of a culture. They are systematic in that there is a fixed correspondence between the structure of the domain to be understood (e.g., death) and the structure of the domain in terms of which we are understanding it (e.g., departure). We usually understand them in terms of common experiences. They are largely unconscious, though attention may be drawn to them. Their operation in cognition is almost automatic. And they are widely conventionalized in language, that is, there are a great number of words and idiomatic expressions in our language whose meanings depend upon those conceptual metaphors.'(George Lakoff and Mark Turner, 1989)

Cross-cultural variation is not a matter of availability or shortage of certain source domains but merely a matter of preference of certain conceptual metaphors. Given a shared generic-level metaphor, English and Chinese might have different source domains to conceptualize the same target domain--love, such as LOVE IS ANIMAL, in Chinese the specific source domain is flying twin swallows or mandarin ducks,; while in English one of the few animals which can be conceptualized as love is dove as in "They sat there billing and cooing till after midnight/It was all lovey-dovey". The metaphors in Chinese imply that the lovers should be as harmonious as birds flying together, or fish and water, which live together harmoniously. However, the English metaphor lacks such implicature.

LOVE IS UNITY is the reflection of one cultural ideology of love: ideal love, which reflects more traditional ideas about love. Being the traditional conception of love, unity of lovers makes them a whole. In a source domain, there are two parts which form a whole and fit one another, and make up a unity that functions as a whole. Love is considered as the spiritual merger of two souls into one.

The two physical parts

The physical joining of the parts

The physical unity

The physical fit between the parts

two lovers

the union of the lovers

the spiritual mergers of the two souls

the harmonious relationship between the two lovers

On the other hand, LOVE IS ECONOMIC EXCHANGE is the reflection of another cultural ideology of love: typical love. Stearns (1994) notes that people nowadays talk more about the rewards the individual should get from a relationship, which is easily related to economic exchange or commodity.

According to Swidler (1988:119), the emerging cultural view of love emphasizes exchange. What is valuable about a relationship is 'what one gets out of it'. The conceptual metaphor LOVE IS EXCHANGE is becoming prevalent in 
American culture. We should admit that exchange metaphor has become a more and popular one in modern Chinese due to the influence of materialism of American culture. However, Chinese people prefer to take love as a pure and romantic emotion, which is not polluted by money or exchange. Hence, people wish lovers to be united as a whole and wish newly married couples "a harmonious union lasting a hundred years" or "bathe in a river of love forever".

\section{CONCLUSION}

Conceptual metaphors are basic to human understanding, thinking, and reasoning. Conceptual metaphors shape the way we think and act, along with our communication. Love is a universal emotion shared by people from different countries. Universality and variation of conceptual metaphors concerning love are mainly because of cultural differences. Because most social, moral, emotional experience is metaphorically constituted, English learners should study and compare the metaphor system in both English and Chinese, which conceptualize the English speakers' experience and Chinese experience respectively.

\section{REFERENCES}

[1] Gibbs, W. (1994). The Poetics of Mind: Figurative Thought, Language and Understanding. Cambridge: Cambridge University Press.

[2] Lakoff, G. and Johnson, M. (1980). Metaphor we live by. Chicago: The University of Chicago Press.

[3] Lakoff, G. (1987) Women, Fire and Dangerous Things. Chicago: University of Chicago Press.

[4] Lakoff, G and Turner, M. (1989). More than Cool Reason. University of Chicago Press.

[5] Lakoff, G. (1993). The Contemporary Theory of Metaphor. In A. Ortony (ed.) Metaphor and Thought. Cambridge: Cambridge University Press.

[6] Lakoff, G. (1996). Moral politics: What Conservatives Know that Liberals Don't. University of Chicago Press.

[7] Lakoff, G and Johnson, M. (1999). Philosophy in the Flesh: The Embodied Mind and Its Challenge to Western Thought. Basic Books

[8] Quinn, N. (1991). The cultural basis of metaphor. Los Angeles: Stanford University press.

[9] Robert C. Solomon. (1990). Love: Emotion, Myth, and Metaphor. Prometheus Books.

[10] Zoltán Kövecses. (2002). Metaphor: A Practical Introduction. New York: Oxford Univ. Press.

Zitu Lv was born in Changchun, China in 1987. She is a postgraduate and is going to receive her M.A. degree in foreign language and literature from Changchun University of Science and Technology, China in 2012.

Yining Zhang was born in Shuangcheng, Heilongiiang Province, China in 1974. She has received her M.A. degree in foreign linguistics and applied linguistics from Changchun University of Science and Technology, China in 2002.

She is currently an associate professor and the supervisor of Zitu Lv in the School of Foreign Languages, Changchun University of Science and Technology, Changchun, China. Her research interests include applied linguistics and pragmatics. 